SHUMIN FENG, Ph.D. ${ }^{1}$

E-mail: zlyfsm2000@sina.com

XIANGHAO SHEN, Ph.D. candidate ${ }^{1}$

(Corresponding author)

E-mail: shen.27@163.com

BAOYU HU, Ph.D. candidate ${ }^{1}$

E-mail: hubaoyu87@163.com

${ }^{1}$ School of Transportation Science and Engineering

Harbin Institute of Technology.

No. 73 Huanghe Road, Harbin, Heilongjiang, 150090,

The People's Republic of China
Traffic in the Cities

Original Scientific Paper

Submitted: Sep. 7, 2015

Accepted: Apr. 12, 2016

\title{
OVER-SUPPLY IN PUBLIC TRANSPORTATION: CASE STUDY OF BUS AND METRO LINES IN HARBIN CITY, CHINA
}

\begin{abstract}
As the two most important modes in public transportation, the coordinated development of bus and metro networks significantly influences the efficiency of public transportation. However, two parallel bus and metro lines belonging to different operators may lead to supply competition and consequently yield over-supply. Taking two parallel bus and metro lines in Harbin city, China as a case study, this paper, drawing on game theory, establishes a utility model based on the two lines' frequencies, and reveals and explains the fundamental reason for the over-supply problem using a Nash equilibrium. In an attempt to resolve this issue, the study proposes a new operation mode: integrating frequencies of the two modes to obtain larger total profits then reallocating the total profits to the two modes. The case study shows that this new operation mode can effectively solve the over-supply problem while satisfying both operators of the two modes, and hence having practical value.
\end{abstract}

\section{KEY WORDS}

public transportation; supply competition; Nash equilibrium; over-supply; game theory; China;

\section{INTRODUCTION}

The two main modes of urban public transportation in China are buses and metros. With the expanding urban scale and socioeconomic development, the metro has received considerable government attention. As of 2014, the metro operates in 20 cities in China, and the total mileage it covers is 2,361 kilometres [1]. However, the rapid development of the metro appears to have impacted the existing bus system. Thus, addressing the relationship between the two modes has become an important issue.

The extant literature mostly focuses on the coordinated development between the bus and metro system. Sun et al. studied the integration of the bus and metro network using multiple goal programming [2]. Chen et al. suggested unifying a transfer network for a more efficient transfer system for the two modes [3]. Chen proposed a fare linkage organism between bus and metro systems [4]. Jin et al. defined the resilience of the metro network to disruption and introduced localized integration with bus services to enhance this resilience [5]. However, these studies have mostly discussed the optimization of the integration of the two systems, and are thus restricted to the public transportation administrator point of view.

By contrast, some studies have recognized the competitive relationship between the two travel modes. For instance, Ma et al. defined the rival area of the bus and metro system by passengers' travel distances, but neglected the competitive game between the two modes [6]. Adriaan et al. analyzed how different market structures - i.e., markets with a monopolistic public transportation operator and those with individual operators for each public transportation link - influence public transportation fares and social welfare [7]. In some countries, such as China, public transportation fares are determined by the government and once determined, remain constant over time. Thus, the key competitive strategy for the operators of both public transportation modes is frequency, or more specifically, supply capacity. Drawing on the actual situation in China, Hu constructed a bi-level model: the upper level determines the best fare, a decision that is contingent on the government, and the lower model establishes the best frequency. Although the result of the lower model deviated from the Nash equilibrium for the two operators, it served as the optimal solution [8]. Using evolutionary game theory, Li described changes in the level of competition between the bus and metro systems based on the scale of metro mileage in a city; however, their study does not discuss measures specific to competition, and mostly offers qualitative descriptions [9]. 
Duplicate bus and metro lines are rather common in China, such as bus line 1 and metro line 1 in Beijing or bus line 104 and metro line 1 in Harbin city, and the rate of repetition between the two modes' stations is more than $85 \%$ for the entire line. The rationale underlying the parallel operations of various travel modes is the provision of diverse traffic channels to improve the reliability of the public transportation system and perfecting the system so that it is more attractive to passengers. However, because it is often the case that bus and metro systems have different operators in China, and as opposed to private transportation they face a relatively similar passenger market, competition between the two modes for passengers is inevitable. Assume that network, fare, and transfer facilities have been determined, and the bus and metro operators have relative control over dispatch frequency; in other words, the two modes mainly compete in frequency.

Assume that a certain area is served by two parallel bus and metro lines and both operators can freely control dispatch frequency as long as it is within the scope of their capacity and satisfies travel demand. Due to the limited passenger flow demand, the average benefit of a single trip for the two modes is relative to total frequency and has a negative correlation when input capacity reaches a certain value, after which an additional trip can result in a decline in total benefit. When determining frequency, traffic operators should consider not only the influence of one more trip on revenue but also its effects on the other operator's choice of strategy; this can be seen as a typical game process.

In an ideal scenario, the competition between the two modes is not encouraged due to the risk of over-supply and the lack of efficiency in the public transport system; hence, a new method that diminishes the influence of competition is needed. In this paper, we examine two parallel bus and metro lines and use game theory to analyze the capacity strategies between the two modes, and propose a new operation mode that enhances the efficiency of the public transportation system. The method can also be expanded to a bi-mode network to promote coordinated development of public transportation, and serve as a theoretical support for public transportation administrators and operators.

The remainder of this paper is organized as follows. Section 2 provides the main methodology of the paper. Section 3 introduces the game model for bus and metro supplies. Section 4 verifies the model with a case study. Section 5 analyzes the over-supply problem and proposes a new operation mode to resolve the problem. Section 6 provides a conclusion.

\section{METHODOLOGY}

In the game between two parallel bus and metro lines, the two players are the bus and metro operators, and the strategy for each player is dispatch frequency. The utility of each player is its profit, which is dependent on its income and cost and is affected by not only its own strategy but also that of the other player.

For accurate game results, a rational and effective utility function is needed; the process used to establish such a function is shown in Figure 1. First, consider a rational travel mode choice model, and calculate the average passenger flow of each trip under different frequency strategies adopted by operators, which provides a series of average passenger numbers for each trip corresponding to each frequency combination. Second, by conducting a multiple regression analysis using the obtained data, establish a function that illustrates the relationship between passenger volume for one trip (dependent variable) and different frequency portfolios (independent variables). Finally, considering the operation cost of each trip and revenue from the fares, build a profit function for the operator of each mode; this function can also be regarded as a utility function.

Given the common passenger market, it is assumed that the utility functions are common to both

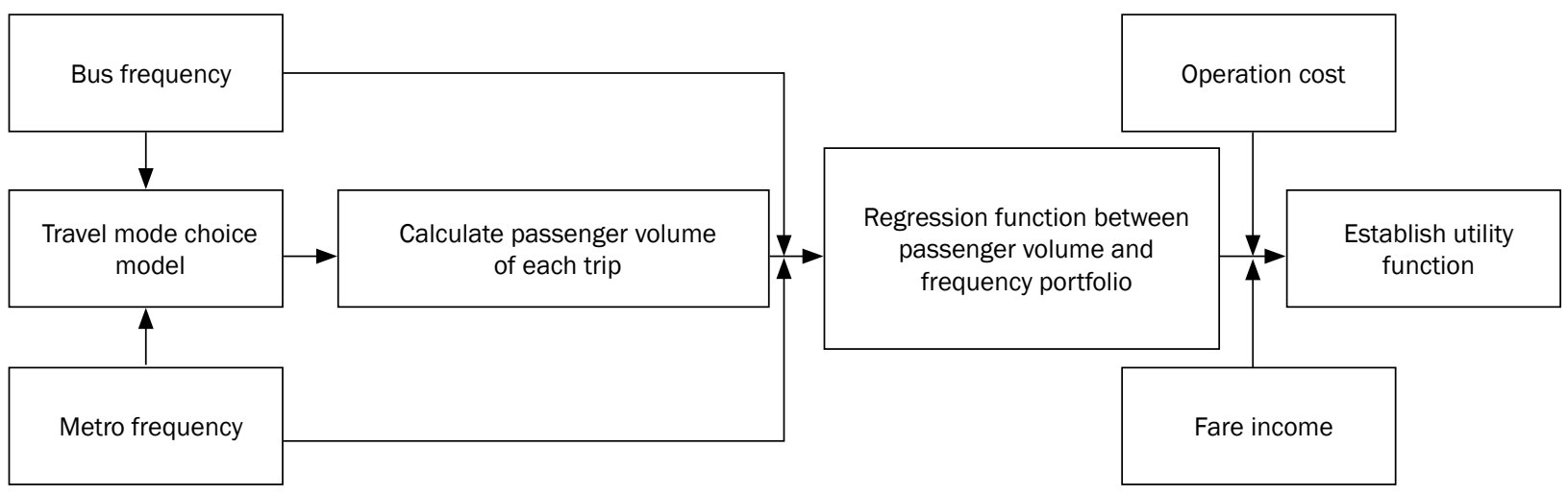

Figure 1 - Process of establishing a utility function Source: own design 
operators. In addition, there is a certain consistency in passengers' travel mode choice in the region and both operators can correctly judge the opponent's utility function on the basis of the operating cost and passenger fare.

Once a utility function is defined for each operator, the Nash equilibrium can be obtained by using the differential method, and using it for further analyses.

\section{MODEL FRAMEWORK}

This section first describes the problem. Then, a two-step modelling framework is presented: (1) establishment of a utility function that takes the bus and metro frequencies as independent variables; (2) analysis of the game process for achieving a Nash equilibrium for the two modes.

\subsection{Problem description and relative variables}

Let us assume two modes of public transportation, bus and metro, in region $D$ in a given period. The total public transportation demand in the region is $Q$ within a given time, which is a fixed value. Both operators regulate their dispatch frequencies, and the total capacity of the two modes can satisfy $Q$. A passenger's choice of travel mode is affected by the frequency of each mode. The cost of each trip and fare per passenger for both travel modes is fixed; considering that we study the case of Harbin city, we set the metro fare to be double the bus fare and its cost to be nearly 7 times the bus cost, as is actually the case. The profit from each mode is determined by passenger volume share and frequency.

The notations used in the model are as follows: $i$ is travel mode, where $i=1$ indicates a bus and $i=2$ indicates a metro; $x_{i}$ denotes the frequency, or trips per hour, and depends on the operator and $x_{i}^{\max }$ is the maximum value of $x_{i} ; q_{i}$ is the maximum passenger volume per trip; $s_{i}$ and $d_{i}$ are supply and demand quantities, respectively, and $u_{i}=s_{i}-d_{i} . R_{i}$ represents the actual passenger volume carried by mode $i$ and $P_{i}$ is the passenger share in mode $i ; P_{i}$ is the actual passenger volume for one trip using mode $i ; y_{i}$ denotes fare, $C_{i}$ is operation costs (mainly labour costs, oil (electric) fees, and depreciation cost of equipment), and $\pi_{i}$ is mode i's profit.

It is noteworthy that $C_{i}$ excludes fixed costs that do not vary by frequency, such as station fees for the bus stops and lighting fees at metro stations.

\subsection{Utility function}

Using the process described in Figure 1, we define the utility functions of the modes as follows:

$P_{i}=f\left(x_{1}, x_{2}\right)$
$d_{i}=P_{i} \cdot Q$

$s_{i}=x_{i} \cdot q_{i}$

$u_{i}=s_{i}-d_{i}$

$R_{1}= \begin{cases}d_{1}+u_{2} & \text { if } u_{1}>0 \text { and } u_{2}<0 \text { and }\left|u_{1}\right| \geq\left|u_{2}\right| \\ s_{1} & \text { if } u_{1}>0 \text { and } u_{2}<0 \text { and }\left|u_{1}\right|<\left|u_{2}\right| \\ d_{1} & \text { if } u_{1}>0 \text { and } u_{2}>0 \\ s_{1} & \text { if } u_{1}<0\end{cases}$

$R_{2}= \begin{cases}d_{2}+u_{1} \text { if } u_{2}>0 \text { and } u_{1}<0 \text { and }\left|u_{2}\right| \geq\left|u_{1}\right| \\ s_{2} & \text { if } u_{2}>0 \text { and } u_{1}<0 \text { and }\left|u_{2}\right|<\left|u_{1}\right| \\ d_{2} & \text { if } u_{2}>0 \text { and } u_{1}>0 \\ s_{2} & \text { if } u_{2}<0\end{cases}$

$R_{1}+R_{2} \geq Q$

$y_{i}=\frac{R_{i}}{X_{i}}$

$x_{i}=1,2,3, \ldots, x_{i}^{\max }$

Equations 1 and 2 indicate the travel demand for mode $i$ and function $f\left(x_{1}, x_{2}\right)$ is the travel mode choice model, which is affected by bus and metro frequencies. Equation 3 gives the supply quantity and Equations 4 through 6 denote actual passenger volume for each mode. Given a certain frequency, the actual acceptance of passenger volume is restricted to supply capacity. That is, if there is a surplus in bus capacity and the metro frequency is insufficient for available demand, the additional passengers will be transferred to the bus and vice versa. Constraint 7 indicates that the total passenger volume for both modes should meet total public transportation demand Q. Equation 8 gives the calculation of the actual passenger volume per trip, which is deemed a dependent variable in the regression analysis. Equation 9 gives the possible choice of $x_{i}$.

According to Equations 1 through 9, a series of $y_{i}$ corresponding to each $x_{i}$ combination can be obtained for different frequency combinations for both modes. Here, we ignore the requirement that $y_{i}$ and $x_{i}$ should be integers; this does not affect the analysis results. Then, by taking $x_{i}$ as the independent variable and $y_{i}$ as the dependent variable, we obtain Equations 10 and 11 from a multiple regression analysis:

$\widetilde{y}_{1}=B_{1}-\omega_{1} x_{1}-\theta_{1} x_{2}$

$\widetilde{y}_{2}=B_{2}-\omega_{2} x_{1}-\theta_{2} x_{2}$

Using the two equations, we formulate the utility functions for the two modes:

$\pi_{1}^{*}\left(x_{1}, x_{2}\right)=F_{1} \cdot x_{1} \cdot \widetilde{y}_{1}-C_{1} \cdot x_{1}$ 
$\pi_{2}^{*}\left(x_{1}, x_{2}\right)=F_{2} \cdot x_{2} \cdot \widetilde{y}_{2}-C_{2} \cdot x_{2}$

\subsection{Nash equilibrium}

If $\left(x_{1}^{*}, x_{2}^{*}\right)$ is a Nash equilibrium, to obtain the equilibrium strategies, we first calculate the derivation of the utility function for each mode and set it as 0 (Equations 14 and 15). The solution for the simultaneous equations is the Nash equilibrium $\left(x_{1}^{*}, x_{2}^{*}\right)[10]$.

$$
\begin{aligned}
& \left.\frac{\partial \pi_{1}^{*}\left(x_{1}, x_{2}^{*}\right)}{\partial x_{1}}\right|_{x_{1}=x_{1}^{*}}=g_{1}\left(x_{1}^{*}, x_{2}^{*}\right)=0 \\
& \left.\frac{\partial \pi_{2}^{*}\left(x_{2}, x_{1}^{*}\right)}{\partial x_{2}}\right|_{x_{2}=x_{2}^{*}}=g_{2}\left(x_{2}^{*}, x_{1}^{*}\right)=0
\end{aligned}
$$

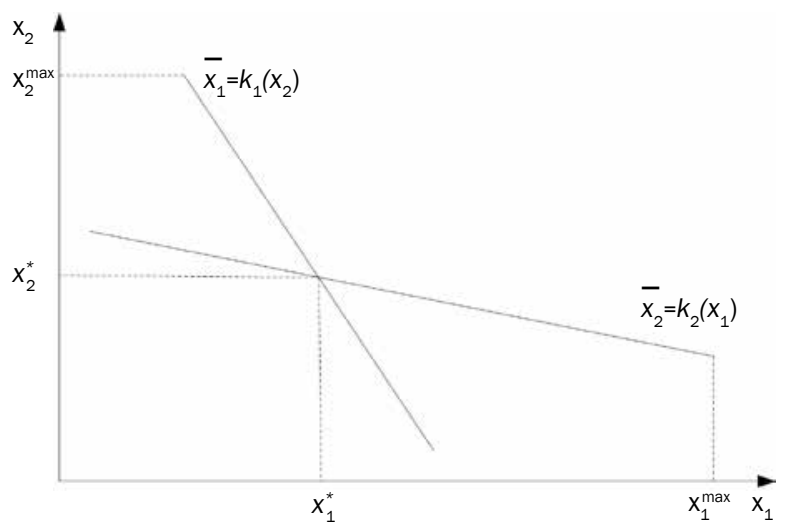

Figure 2 - Reaction functions for the optimal frequencies and the Nash equilibrium

Source: own design

To better understand the Nash equilibrium, we introduce the concept of a reaction function (Figure 2). If the frequency of metro $x_{2}$ is given, then bus frequency $x_{1}$ is optimal only when it satisfies $\frac{\partial \pi_{1}\left(x_{1}, x_{2}\right)}{\partial x_{1}}=0$. Thus, when $x_{2}$ is fixed, the optimal output can be expressed as $\bar{x}_{1}=k_{1}\left(x_{2}\right)$, that is, $\bar{x}_{1}$ is the best strategy when $x_{2}$ is given as the bus operator's reaction function. Similarly, we define the reaction function $\bar{x}_{2}=k_{2}\left(x_{1}\right)$ for the metro. Given that the utility function is linear, the two reaction functions are shown as two lines in Figure 2 and the point of intersection is the Nash equilibrium.

\section{CASE STUDY}

In this section, we apply the proposed modelling framework to analyze the game process of the supply strategies of two parallel bus and metro lines in the city of Harbin, China, and assess the feasibility of the modelling framework by comparing with actual operations.

\subsection{Base data and travel mode choice model}

We take as an example the competition between bus line 104, operated by Harbin Public Trolley Company, and metro line 1, run by Harbin Metro Operating Company, in Harbin city, China. The length of bus line 104 is $16.9 \mathrm{~km}$ and that of metro line 1 is $17.4 \mathrm{~km}$, with both running parallel for $15.8 \mathrm{~km}$. The objective time is from 9:00 to 10:00, the total demand for public transportation is $Q=600$, and the possible frequency of the two modes is $x_{1} \in[1,30]$ and $x_{2} \in[1,20]$ during this period.

The logit model based on random utility theory is the most widely used among the existing travel choice models [11]. Thus, this study also adopts the logit model to describe the travel behaviour. Since there are only two types of travel modes, we adopt the following binary nominal logit as the travel mode choice model:

$$
\begin{aligned}
& P_{1}=\frac{\exp \left(V_{1}\right)}{\exp \left(V_{1}\right)+\exp \left(V_{2}\right)}, \\
& P_{2}=\frac{\exp \left(V_{2}\right)}{\exp \left(V_{1}\right)+\exp \left(V_{2}\right)},
\end{aligned}
$$

$V_{i}=-1.22 T_{i}-0.231 F_{i}+0.337 E_{i} \quad i=1,2$

Equation 17 is the traveller's utility function obtained from survey data. $T_{i}$ indicates travel time and is composed of the average waiting time $T_{i}^{w}$ and in-vehicle time $T_{i}^{r}$ (see Equation 18). $T_{i}^{w}$ is determined by frequency $x_{i}$ (see Equation 19):

$$
\begin{aligned}
& T_{i}=T_{i}^{w}+T_{i}^{r} \\
& T_{i}^{w}=\frac{1}{x_{i}} \cdot \frac{1}{2}
\end{aligned}
$$

Table 1 - Value of relevant variables

\begin{tabular}{|c|c|c|c|c|c||}
\hline \hline Variable & Value & Unit & Variable & Value & Unit \\
\hline \hline$q_{1}$ & 160 & $\mathrm{p}$ & $q_{2}$ & 1500 & $\mathrm{p}$ \\
\hline $\mathrm{F}_{1}$ & 1 & yuan & $\mathrm{F}_{2}$ & 2 & yuan \\
\hline$T_{1}^{r}$ & 0.63 & $\mathrm{~h}$ & $T_{2}^{r}$ & 0.35 & $\mathrm{~h}$ \\
\hline$E_{1}$ & 1 & - & $E_{2}$ & 3 & - \\
\hline$C_{1}$ & 85 & yuan & $C_{2}$ & 600 & yuan \\
\hline
\end{tabular}

Source: own formulation

$F_{i}$ is the fare of mode $i$ per passenger; $E_{i}$ is the qualitatively determined value of the overall environment for mode $i$, developed by mainly considering comfort, convenience, and reliability, where the value of $E_{i}$ ranges from 1 (poor environment) to 5 (comfortable environment). This study assumes a private car to be the most comfortable mode of transportation, and accordingly, sets the travel environment value of a bus to 1 
and that of the metro to 3 . Other related variables are shown in Table 1.

\subsection{Game process}

Inserting the relevant variables into Equations 1 through 9 , we obtain a series of $y_{1}, y_{2}$ corresponding to $x_{1}, x_{2}$. Because $x_{1}^{\max }=30$ and $x_{2}^{\max }=20$, there are a total of 600 types of strategy combinations, excluding the ones that do not satisfy restraint 7 , which leaves us with a total of 545 types of combinations. Using these data groups, we regress the function link between $\widetilde{y}_{i}$ and $x_{1}, x_{2}$ :

$$
\begin{aligned}
& \tilde{y}_{1}=192.381-3.979 x_{1}-0.731 x_{2} \\
& R^{2}=0.888 \\
& \widetilde{y}_{2}=1199.315-3.067 x_{1}-55.474 x_{2} \\
& R^{2}=0.768
\end{aligned}
$$

$R^{2}$ indicates the goodness of fit and all coefficients of the regression functions satisfy the t-test at the 0.01 level. Next, incorporating Equations 12 and 13, and given the requirement of the first derivation, we obtain the following simultaneous equation:

$$
\left\{\begin{array}{l}
107.381-7.958 x_{1}^{*}-0.731 x_{2}^{*}=0 \\
1798.63-6.134 x_{1}^{*}-221.896 x_{2}^{*}=0
\end{array}\right.
$$

Solving the above equation provides us a Nash equilibrium solution:

$$
x_{1}^{*}=12.73 \approx 13, \quad x_{2}^{*}=7.75 \approx 8
$$

Then, inserting them in the following utility function gives us the results presented in Table 2:

$$
\pi_{i}=F_{i} \cdot x_{i}^{*} \cdot y_{i}-C_{i} \cdot x_{i}^{*}
$$

Table 2 - Nash equilibrium results

\begin{tabular}{|c|c|c|c||}
\hline$i$ & $x_{i}$ & $y_{i}$ & $\Pi_{i}$ \\
\hline \hline 1 & 13 & 147 & 808 \\
\hline 2 & 8 & 511 & 3,375 \\
\hline
\end{tabular}

Source: own calculation

According to the survey, the actual bus frequency is 15 trips per hour, which is slightly higher than the game result. This can be attributed to the fuel subsidy implemented by China's government, which reduces operating cost to less than 85 yuan per trip for a bus. The lower cost may result in the increase in frequency. As for the metro, the actual frequency is eight trips per hour, which is consistent with the game result. Overall, the simulation results coincide with the actual operations, and thus, the game model can be considered feasible and accurate. Because the specific number of fuel subsidies could not be obtained from the available open information, in a later analysis in Section 5, we continue to set the frequency of the Nash equilibrium to 13 trips per hour.

\section{RESULT AND DISCUSSION}

The optimal solution for individual operators as per game results is the Nash equilibrium. However, it may not be optimal from the perspectives of a traffic channel's total profit. Suppose the goal is to maximize total channel profits and to ensure a single trip is not too crowded or empty. In this case, we set one-trip capacity constraints as $y_{1} \in[80,130] . y_{2} \in[500,1000]$, which should also satisfy Equations 1 through 9. Then, the optimal solution in terms of frequency is 16 trips per hour for buses and 4 trips per hour for metros, with a total channel profit of 6,215 yuan. However, an optimal solution may not be preferable as the goal is to foster metro passenger flow by increasing its frequency, and thus, a satisfactory solution is chosen: six trips per hour. A comparison of the three solutions is shown in Table 3.

According to Table 1, the capacity per trip values of the two modes are $q_{1}=160$ and $q_{2}=1,500$, respectively; the supply capacity of mode $i$ can now be written as $s_{i}=q_{i} \cdot x_{i}$.Thus, the value of $\left(s_{1}+s_{2}\right)$ in Table 3 can be obtained; the bus fare is 1 yuan per passenger and metro fare is 2 yuan per passenger, and the cost of the bus is 85 yuan per trip and that of the metro is 600 yuan per trip. Then, according to Equation 23, we can calculate $\Pi_{1}$ and $\pi_{2}$, and obtain the value of $\left(\pi_{1}+\pi_{2}\right)$ in the table.

As shown in the table, in comparison to the optimal and satisfactory solutions, the Nash equilibrium provides the highest supply and obtains the lowest profits, which can be regarded as the over-supply problem. Such a situation can be explained by using two game models, the Cournot competition model and the "tragedy of the commons" model.

Under Cournot competition, there are two firms producing homogeneous products and supplying the same market. Firms simultaneously compete in quantity, and generally, seek to maximize profits on the basis of their competitor's decision. In such a situation, competition may result in greater total output but

Table 3 - Comparison of the three solutions

\begin{tabular}{|c|c|c|c|c|c|c|c|c||}
\hline & $x_{1}$ & $x_{2}$ & $y_{1}$ & $y_{2}$ & $s_{1}+s_{2}$ & $\Pi_{1}$ & $\Pi_{2}$ & $\Pi_{1+} \Pi_{2}$ \\
\hline \hline Nash equilibrium & 13 & 8 & 147 & 511 & 14,080 & 808 & 3,375 & 4,182 \\
\hline Optimal solution & 16 & 4 & 127 & 998 & 8,560 & 665 & 5,550 & 6,215 \\
\hline Satisfactory solution & 16 & 6 & 122 & 674 & 11,560 & 597 & 4,485 & 5,082 \\
\hline
\end{tabular}

Source: own calculation 


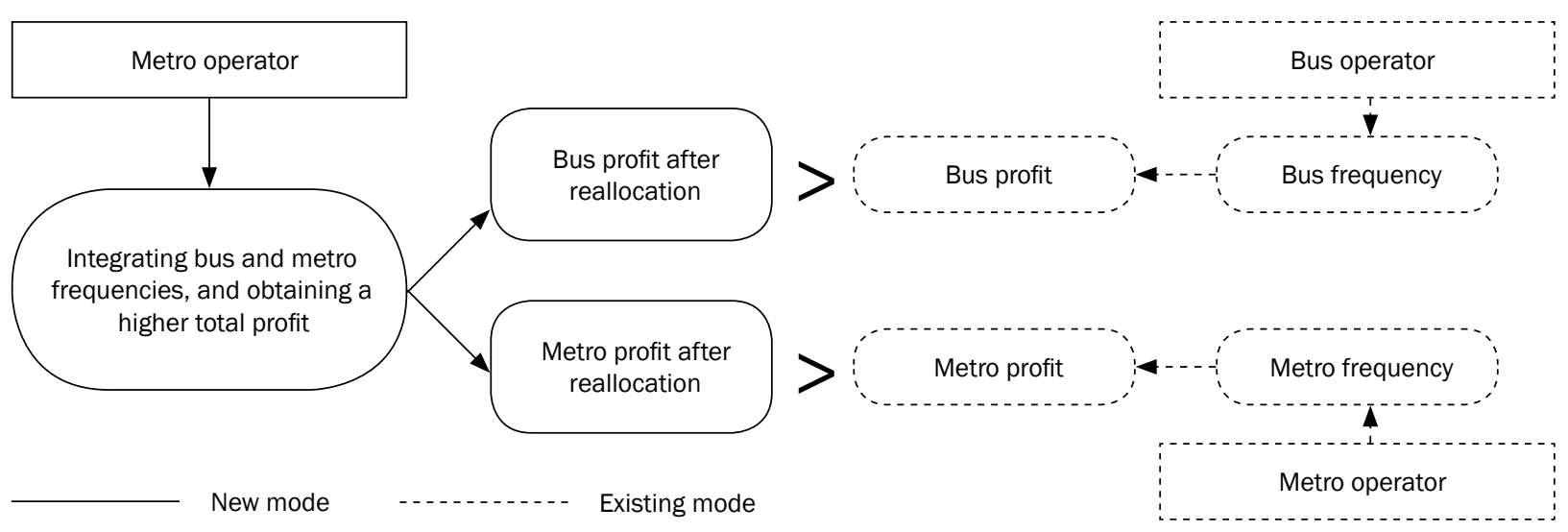

Figure 3 - Comparison between existing and new operation patterns Source: own design

lower total profits as compared to under a monopoly. Although traffic services offered by the bus and metro systems are not entirely homogeneous, both compete in a similar service market. This study establishes a game model using frequency as the strategy, which is similar to output, and thus, the results of Cournot competition can also be used to illustrate the over-supply problem resulting from competition between the two modes of transport.

Second is the tragedy of the commons model. According to the model, public products with unclear property rights can be used by anyone and may lead to the excessive use of a resource. For example, suppose that $\mathrm{n}$ farmers co-owned a piece of grassland. Each farmer has the freedom to herd sheep on the grass, and accordingly, every farmer plans the number of sheep for spring. Due to the existence of a competitive relationship, the total number of sheep from $n$ farmers will be greater than the optimum feeding amount that does not damage the resource. Thus, the model explains two problems: overuse of public resource and excessive number of sheep on the grass; this also applies to the bus and metro systems. Assume that grass resources are bus and metro passengers, farmers are the operators, and herding sheep denotes trips. In this case, over-herding is synonymous with the over-supply problem. In other words, in a competitive environment, the total amount of output for a bus and metro will be higher than the best supply value.

As shown from the case study results, the Nash equilibrium is not the optimal or satisfactory solution because it entails over-supply of transportation capacity. As a solution, the tragedy of the commons model suggests clarifying a clear and stable property for the public resource (passengers); however, this model is not useful in the case of public transportation because passengers cannot be coerced into choosing a specific travel mode. As for the Cournot competition model, we see that, as compared to duopoly competition, monopoly operations can reduce supply and increase profits. Thus, drawing on this theory, we suggest an "integrated-supply, profit-reallocation" model to solve the over-supply problem resulting from competition. Figure 3 is a comparison of the existing and new patterns of operation.

Integrating frequencies means one of the bus and metro operators integrates the frequency of both modes. The trend in public transportation development suggests that the metro plays a key role, and thus, we propose that metro operators lead the process of integrating the capacity supply of the two modes for the attainment of a satisfactory solution.

Second, the profits from frequency integration should be reallocated so that after reallocation, the profits are higher than those obtained from the Nash equilibrium, which is a prerequisite for the new operation mode. In fact, as Figure 3 indicates, the bus/metro operator's profit after reallocation is larger than that under Nash equilibrium.

Next, Harbin city is used as a case study to more specifically explain the proposed model. First, to integrate the frequencies of bus line 104 and metro line 1 , the metro operation company requests the right to dispatch frequency for bus line 104 from the public trolley company, and then, attempts to implement a satisfactory solution (Table 3), obtaining a total profit of 5,082 yuan. In the next stage, the profits are reallocated. Assuming that the bus operator is allocated 1,000 yuan, the metro operator reserves 4,082 yuan. Thus, both the bus and metro operators earn more revenue as compared to before integration.

Unfortunately, this new operation mode increases the average waiting time for a metro passenger from 3.75 minutes to 5 minutes. However, because the difference is small, we consider it to be within the acceptable range. Furthermore, the metro operations company can take certain measures to reduce the perception of waiting time, for example, by providing free newspapers. For bus passengers, the average waiting time decreases from 2.3 minutes to 1.8 minutes. 


\section{CONCLUSION}

This paper addresses the problem of over-supply in parallel bus and metro lines, using a case study of Harbin city, China. The three main conclusions are as follows.

1) A game comprising two parallel bus and metro lines is played and supply capacity is estimated. If the per-passenger fare and per-trip cost are given, and the two modes belong to different operators, the players compete in frequency. The frequency strategy of one mode affects the utility of the other mode and vice versa.

2) Accordingly, a game model is established and a solution for the Nash equilibrium is obtained for the case of Harbin city. The results give that the frequencies of the Nash equilibrium are in line with the actual operations of the two modes. However, the solution is not optimum with regard to social benefit, as there arises over-supply. Two classic game theory approaches - Cournot competition and tragedy of the commons - are applied to explain the causation of over-supply in public transportation.

3) For solving the over-supply problem, a new operation mode is proposed. First, the metro operator integrates both bus and metro frequencies; the total profit thus obtained being larger than that obtained under the Nash equilibrium. Second, the obtained total profit is reallocated to the two operators such that each operator's profit is larger than its profit under Nash equilibrium. Hence, the new operation mode is an effective solution for the over-supply problem.

The theory and method proposed in this paper can also be extended to bus and metro networks. One of the factors leading to the high cost of the public transportation system is over-supply. Since this cost is shared by the government and operation firms, the proposed operation mode can not only improve the efficiency of the public transportation system but also reduce the burden of financial subsidies.

\section{ACKNOWLEDGMENTS}

The authors thank the National High Technology Research and Development Program ("863" Program) of China (2014AA110304) for supporting their research.

\author{
1. 冯树民. 博士, 教授 \\ Email: zlyfsm2000@sina.com \\ 哈尔滨工业大学交通学院. \\ 中国黑龙江省哈尔滨市黄河路73号, 邮编; 150090. \\ 2. 申翔浩 博士研究生 \\ Email: shen.27@163.com \\ 哈尔滨工业大学交通学院. \\ 中国黑龙江省哈尔滨市黄河路73号, 邮编; 150090. \\ 3. 胡宝雨. 博士研究生 \\ Email: hubaoyu87@163.com
}

哈尔滨工业大学交通学院.

中国黑龙江省哈尔滨市黄河路73号, 邮编; 150090.

公共交通的过度供应问题: 以中国哈尔滨市常规公 交和轨道交通线路为例

摘要:

作为最重要的两种公共交通方式, 常规公交与轨道 交通的协调发展对于公共交通系统的运营效率产生 重要影响。然而, 重复运营的两条常规公交与轨道 交通线路由于归属于不同运营者，会产生供应竞 争，继而引发过度供应问题。以中国哈尔滨市两条 平行运营的常规公交和轨道交通线路为例, 利用博 弯理论, 建立两种方式运营者的基于发车频率的效 用模型, 并利用纳什均衡揭示并解释了过度供应产 生的原因。为了解决该问题, 提出了先整合发车频 率, 再分配总利润的新的运营模式。案例分析证明 该新思路能够有效解决过度供应问题, 能让两种方 式运营者都得到满意结果，因此具有实践意义。 关键词:

公共交通; 供应竞争; 纳什均衡; 过度供应; 博弯 论; 中国

\section{REFERENCES}

[1] China Association of Metros. Urban metro annual statistical analysis report; 2014. Available from: http://www. camet.org.cn/sjtj/201505/t20150513_407677.htm

[2] Sun Y, Sun X, Kong Q, Song R, He S. Methodology of bus network optimization and adjustment under operation of new urban rail transit line [in Chinese]. Journal of the China Railway Society. 2014;36(3):1-8.

[3] Chen X, Lin G, Yu L. Modeling operation scheduling coordination between urban rail system and bus system [in Chinese]. Systems Engineering-Theory \& Practice. 2009;29(10):165-173.

[4] Chen J. Research on urban rail transit and bus prices coordination [MS thesis] [in Chinese]. Harbin, China: Harbin Institute of Technology; 2010.

[5] Jin JG, Tang CL, Sun L, Lee D. Enhancing metro network resilience via localized integration with bus service. Transportation Res E-Log. 2014;63:17-30.

[6] Ma C, Wang Y, Chen K. Competition model between urban rail and bus transit [in Chinese]. J Transp Syst Eng Inf Technol. 2007;7(3):140-145.

[7] Van der Weijde AH, Verhoef ET, van den Berg VAC. Competition in multi-modal transport networks: a dynamic approach. Transport Res B-Meth. 2013;53:31-44.

[8] Hu X. Research on participators' economic decision-making model of urban passenger transportation system [PhD thesis] [in Chinese]. Harbin, China: Harbin Institute of Technology; 2013. p. 63-80.

[9] Li L. Study of competitive theory and method of urban rail transit passenger flow [PhD thesis] [in Chinese]. Wuxi, China: Jiangsu University; 2012. p. 63-92.

[10] Wu G, Lv ZZhouyang L. Principles and application of game theory [in Chinese]. 1st ed. Nanjing, China: Southeast University Press; 2009. p. 22-59.

[11] Soora R, Harry T. Applications of theories and models of choice and decision-making under conditions of uncertainty in travel behavior research. Travel Behaviour and Society. 2014;1(9):79-90. 